\title{
STUDENT ISSUES IN DISTANCE EDUCATION PROGRAMS: DO INTER-INSTITUTIONAL PROGRAMS OFFER STUDENTS MORE CONFUSION OR MORE OPPORTUNITIES?
}

\author{
Susan Fey, Mary Emery, and Cornelia Flora \\ North Central Regional Center for Rural Development
}

\begin{abstract}
The Community Development Master's Program is an inter-institutional, trans-disciplinary degree program that began in 2005 online at five participating universities in the North Central region. This article discusses outcomes of interviews with current and past students in the program to determine if a multi-institutional program, versus a program run by one university, makes for more or different struggles and/or opportunities for the online learner. Sloan-C's five pillars for online learning are used to frame the findings. Through qualitative data collection and analysis, researchers in this study worked to find out if having more institutions involved in a distance education program caused students to leave the program, or if it measured up similarly to online programs offered by one university, in terms of student challenges.
\end{abstract}

\section{KEYWORDS}

Inter-institutional, Five Pillars, Retention, Student Success, Drop outs

\section{INTRODUCTION}

More and more students in recent years have decided to continue their education through online master's programs. Students choose these programs because they can maintain their careers and family life, as many are unable to move to a university campus for three or more years. Students also like the flexibility and convenience that an online program offers [1,2]. Wilde and Epperson [3] found that "The ability to remain employed, study after hours, and maintain family and community relationships relatively undisturbed all prove to be powerful reasons for choosing distance programs." Online programs, up until recently, have been offered by one university through one form of teaching technology such as WebCT and BlackBoard. However, many institutions find that scarce resources and instructors make collaborating with other institutions to fill gaps in the curriculum and faculty a necessity. Students who enroll in an inter-institutional degree program take courses from multiple universities in several different formats, including various technological interfaces and use of audio and video technology within the courses. Students in the Community Development Online Master's Program use Web CT, Blackboard and K-State Online throughout their course of study in the program; sometimes they are using all three in one semester. As more universities decide to offer collaborative degree programs, we wanted to explore how taking online courses from multiple universities impacts students' experiences and success as well as recruitment and retention. To explore these, we utilized the Sloan Consortium's five pillars of quality for online education: learning effectiveness, cost effectiveness and institutional commitment, access, faculty satisfaction and student satisfaction [4]. Inter-institutional programs working together to meet these pillars of quality share resources, yet each institution presents a different face to the students. One might expect that the need to interact with different institutions, registrar offices, and technology would create additional barriers for the online student. This paper presents the results of the research on student success 
Student Issues in Distance Education Programs:

Do Inter-institutional Programs Offer Students More Confusion or More Opportunities?

in a multi-institutional context by reporting on the experiences of students enrolled in an online transdisciplinary, inter-institutional master's program in Community Development to determine if the multi-institutional context impacts students' experiences within the five pillars.

\section{BACKGROUND OF THE PROGRAM}

Michael and Balraj [5] discuss the main reasons why institutions engage in inter-institutional degree programs: "Primarily, institutions establish joint degrees to (1) meet the need of a changing profession, (2) restructure degree programs to become more interdisciplinary, (3) respond to enrollment needs, and (4) enhance the specialization nature of some degree programs." For these reasons an inter-institutional degree program makes sense; these programs allow institutions to provide programs that may otherwise not exist. The authors also cite that there are some disadvantages, in so far as students switching between sites and the approval process within all of the universities. In the Community Development program it has been challenging to gain approval at all of the universities within the same timeframe, but that did not mean the program could not run. Students simply could not enroll in an institution that was not approved; however, this has not slowed down enrollment. Students are willing to enroll in a partner institution. Additionally, our study did not show that students had difficulty switching between sites online. They may have preferred one interface over another, but they did not cite this as a reason for leaving the program.

Moxley [6] points out that "Inter-institutional distance education program alliances enable collaborating universities to deliver online academic programs that capitalize on their collective technological and human capacities." The Community Development Online Master's Program is an asynchronous degree program offered through the Great Plains IDEA (Interactive_Distance Learning Alliance). It is not a collaborative degree only because it involves several universities; it also involves several different disciplines. Faculty from Planning, Architecture, Sociology, Economics, Native American Studies, Natural Resources, Communications, and Agriculture all offer courses in the program. The program officially began in Fall 2005 with courses offered by Iowa State University, South Dakota State University, and the University of Nebraska. At the time the student interviews were conducted, the program was not yet approved at North Dakota State University, Kansas State University, or the University of Missouri, but courses were officially offered in all these institutions by Spring 07. With the help of a USDA Higher Education Challenge Grant, The North Central Regional Center for Rural Development, housed at Iowa State University, provides day-to-day management and leadership of the program. The program started primarily to "meet the needs of a changing profession," as well as to enhance programs already in place. At the time of its inception, it was the only online Master's Degree in Community Development available; all others we studied required some sort of residency. The program offered two courses in the Fall and two in the Spring of 2006. In Spring 06 we conducted interviews with current and former students in the Spring of 2006 to investigate their viewpoint of the program and to better understand the program's progress. Current students included those who either were formally enrolled in the program through one of the universities or those enrolled in one or more courses, but did not formally enrolled in the degree program. Former students either decided to drop courses, drop the program, or end their coursework because they had supplemented an already existing Program of Study with some of Community Development program's courses and did not intend to take more courses.

\section{RESEARCH ON DISTANCE EDUCATION: FACTORS THAT AFFECT STUDENT RETENTION}

Research on distance education programs suggests that students who learn from a distance enroll and drop courses for many of the same reasons: family commitments, jobs, time, and technology; all of these 
elements make distance education attractive, but also cause students to become overwhelmed and drop out. Additionally, students who succeed in distance education programs create ways to make it work for them, mainly through coordinating their schedules and surrounding themselves with supportive people. The purpose of this literature review is to find out why students leave distance programs offered by one institution and if they leave for reasons that relate to the reasons for attrition in our multi-institutional program.

Piercy and Lee [9] found that students in a graduate distance program in family relations offered through Utah State University appreciated the flexibility and freedom the program provided them. Students thought the instructors were very competent and found the material in the program led to the enhancement of critical thinking skills. Downfalls of the program included a lack of information about the program from the very beginning and a need for more mentoring. Students wanted a bit more flexibility in their coursework in terms of choosing more electives. They also wanted more ease in gaining library materials from the university. The authors also discussed how interested students ended up not enrolling because of family situations, change in career, or other educational opportunities. Distance students appreciate the ability to continue to work and maintain their obligations in the community and in their family while gaining a master's degree.

Retention in distance education programs remains a significant challenge, as Piercy and Lee [9] point out. They offer several strategies for improving retention, including frequent communication and peer mentoring, as well as making sure information is passing back and forth in a fluid motion. There are seemingly many factors when it comes to retention. Nash [10] focuses on why many distance students end up dropping out of a program of study. He cites several factors that lead to dropping out of a program with time being a leading factor, as well as lack of preparation for the curriculum, lack of support, and difficult in contacting faculty. Garland [11] found that students often cite the lack of time as a reason for dropping out of a distance education program. However, she also discusses that this can often be "a simplified explanation of the difficulties they were experiencing." She found this to be true with other reasons students cited as well; even when students said they did not have enough money, there were usually other reasons why the students dropped, such as "a lack of prerequisite knowledge, [and] lack of peer and family support..."

As Valenta et al. [1] points out, cost is an issue for some students [12]. Some students feel that they should be provided financial assistance from the institution to pay for equipment and Internet charges. Access can also be difficult for some students who do not have the right equipment and technology. Lao and Gonzales [13] cite discussion from one of their students who said that not having the right version of an Internet browser can make or break a class. Many students in the Community Development program live and work in rural settings, and rural populations often face challenges with accessing high-speed Internet [14]. Lack of high-speed access can also be a barrier to success in online programs.

Pierrakeas, et al. [15] found that students were dropping out of a Greek graduate distance education course because of personal reasons, professional reasons, misunderstanding of academic rigor, lack of interest and lack of time. Much like our study, they found that non-traditional graduate students who had been away from school for a long period of time had a difficult time readjusting to the rigor of graduate coursework. Likewise, these students found it difficult to balance their professional, family and academic lives. Williams, et al. [16] cite Powell, et al.'s [17] classification of factors related to success and retention: Predisposing characteristics, life changes, and institutional reasons. These factors directly connect to what we heard from our students. 
Atack [18] found through a study of nursing students taking online coursework, students new to online learning can find it somewhat intimidating and that the learning curve can be high. Learning how to be a student in a graduate program as well as how to use online learning technology proved difficult for some of the students in Atack's study. She also found that communication over technology can sometimes be an obstacle and create problems for students. This was the case for the Community Development students; additionally, we found that some obstacles in students' lives go far beyond the technology.

When it comes to student learning online, the literature points to the importance of promoting strong collaboration and communication in the class [19, 20, 21, 22] Fung focuses on the difficulty in facilitating genuine discussion in online classrooms, because students sometimes do not have the time it takes to post a thoughtful comment. Or, students lose interest in the conversation, but post a comment simply to gain credit. This can be a vicious cycle in class discussion; Haythornthwaite [21] offers several recommendations for improving and facilitating online collaboration. It is important for online instructors to create a positive forum for discussion so that students do not "disappear" from the discussion and ultimately drop out of sight. Students, in turn, get more from the course if they are engaged in the material with their instructor and peers. Further, Lao and Gonzales [13] discuss the need to respond to students in a timely manner, "in spite of the amount of work that is required when writing this feedback."

From scanning the literature on online education, it seems that the issues are very much the same in all programs offered through one institution or many. Students like the flexibility of distance education, but they do not always anticipate the time needed for coursework. Students sometimes find technology to be a barrier to learning online, if they are new to it or have outdated technology or limited access. And, retention in distance education is an issue because the student population often includes non-traditional students who are older and have full-time jobs and family commitments.

From the review of the literature, we understand that students within our inter-institutional program struggle with many of the same issues as students mentioned in the research. Students in our program did not cite that the multiple institutions and technological interfaces created stumbling blocks. They cited the same reasons in the existing literature. Therefore, we moved on to our findings, which suggest that retention issues closely relate to the issues that have already existed.

\section{PURPOSE OF THE EVALUATION}

We developed the evaluation process primarily to learn why some students succeeded in the program while others dropped out. We felt some kind of person-to-person follow up was necessary because distance students in any online program do not have face-to-face access to instructors or advisors, and thus key issues may escape faculty notice. Research indicates that these issues often impede a student's progress and contribute to a spiral of non-attendance leading to failure. Because many students may not be comfortable with bringing such issues up in class, they may not be discovered until after a student drops the course or program, making it too late to "fix" the problems. To understand the issues that students faced in the Community Development program, we solicited their opinions about the different facets of the program including the inter-institutional context, the various approaches to technology, the faculty roles, the coursework, the time needed for successful completion, their support network, and finances. Additionally, we wanted to learn from the successful students the techniques and habits they employ to make online learning in an inter-institutional program work for them.

This evaluation process was particularly important for us because once the program began, student retention quickly became a dominant concern, and despite efforts to connect with each student, we still 
had many "drops" by the end of the first semester (see Table 1). In particular we wanted to determine if the inter-institutional online master's program created too much confusion for students and thus influenced their decision to drop out. Perhaps offering the program from more than one institution was not working. After carefully reviewing the literature on online degree programs and interviewing current and past students, we found that students' experiences in this inter-institutional online program closely mirrored those of students participating in online programs offered by a single university, in that students were citing the same difficulties: time management, finances, course difficulty, and life changes.

Table 1: Student Retention Numbers

\begin{tabular}{|l|c|c|}
\hline & $\begin{array}{l}\text { Number of students } \\
\text { beginning in } \\
\text { combined courses }\end{array}$ & $\begin{array}{l}\text { Number of Students } \\
\text { dropped course or } \\
\text { program altogether }\end{array}$ \\
\hline Semester 1 Fall 2005 & 22 & 12 \\
\hline Semester 2 Spring 2006 & 17 & 8 \\
\hline
\end{tabular}

In designing an appropriate evaluation process, we determined to use the positive deviance methodology with successful students. Based on the Appreciative Inquiry approach, the positive deviance methodology focuses on learning what is working well by studying the patterns, attitudes, and actions of those who are successful [7]. Using Appreciative Inquiry provide us with a lens through which we could view the student's perceptions from a systemic perspective; it provided us with a method for looking at student situations from a holistic viewpoint [8]. We also applied Appreciative Inquiry techniques to the interviews with students who dropped, soliciting from them the things that had worked well for them and asking them to tell us what would need to happen for the program to have worked better for them.

\section{EVALUATION INSTRUMENTS}

For the purpose of this evaluation, we developed two different instruments. One instrument includes a list of questions for current students, and the other includes a list of questions for past students who either dropped a course or the program (Box 1 and 2). An asset-based approach was used to design the questions. Instead of focusing on problems, questions were created around the strengths, opportunities, and possibilities of the program. Students were contacted about what was going well and the opportunities they saw for the future. We also asked them to give us three wishes for the program.

We developed specific questions about the program from student feedback over email and with instructors, program managers and campus coordinators, as well as from conversations in faculty meeting conference calls. In total, we collected responses from 20 current and former students over the course of a few months. If students were unreachable by phone, we immediately sent email messages, and students filled out the questionnaire and sent it back. We also sent the questionnaire by email if students were unable to find time for a phone interview. After three attempts to reach unresponsive students, we did not pursue them any further. There were five students who were not interviewed and did not fill out questionnaires because they did not return phone calls or email messages. Reasons for the lack of communication are unknown except in one case where the student had health problems; however, reasons could relate to a lack of trust or understanding about why we were approaching them, especially students who dropped.

Answers to the interview questions were coded and put into NVIVO, a qualitative software package. After all of the interviews were coded, reports were generated by theme and then analyzed for this report. 


\section{Box 1: Data gathering instrument for current students}

1. What drew you to this program?

2. We know that one of the issues with taking distance education classes is managing all elements of our lives to fit it into a schedule. What works well for you, in terms of making your schedule work and remaining in the degree program, i.e., how do you manage your time?

3. What are some of the strategies you employ to balance everything in your life: home, work, community, financial, and school, etc. What advice would you give to others?

4. What did you know about taking distance education courses before this experience? What would you have liked to know?

5. Are there others in your community taking courses? If so, do you study with them or share resources (books, Internet access, etc.)?

6. Family support can be an important element when completing an educational program. In what ways has your family been a positive part of completing the program?

7. Please talk a bit about the support you may have received at work or in the community? Could you share a specific story that shows how this support has been useful to you?

8. How have the instructors been helpful in meeting your needs? Can you talk about a time when one of your instructors showed flexibility with your schedule, or helped you manage the conflicting demands on your time?

9. What advice would you give someone who is beginning the degree program and may be concerned about demands on their time?

10. To what degree if any, has the need for financial support been an issue for you?

11. Have you pursued any educational loans or scholarships? If yes, how did you learn about these financial resources?

12. How has having a reliable computer with Internet access been a factor in completing your coursework? Do you have high speed Internet and a reliable computer in your home? If not, do you have access to one? Do you have a quiet place to do your homework without distractions?

13. If we were to design a for credit orientation seminar for this program, what do you think it should include?

14. If you could have three wishes for this degree program, what would they be? 
Box 2: Data gathering instrument for former students

1. What interested you in the degree program? What were you hoping for when you signed up for the classes?

2. Which of the following played a role in your decision to drop the class?

- Scheduling - finding time to work on the classes

- Support—having people around you support your need to spend time on the classes, did you know others who were talking classes with whom you could study?

- Technology - did you have the technology resources you needed?

- Understanding the program — was there too much confusion at the beginning?

- Financial—was the cost of the courses a factor in your decision?

3. If you could have three wishes for the program, what would they be? If these needs would have been met, would you still be taking courses in the program?

4. If we were to design a for credit orientation seminar for this program, what do you think it should include

5. Do you think you might take courses for this program in the future? How could we be helpful to you? What courses interest you most?

\section{OUR FINDINGS}

Findings from the study fit well into the Sloan pillars, allowing us to connect the study results with current best practice in the field. They also offer a way to organize the themes that emerged from the study as well as the suggestions and strengths we will build on as we work to improve the program. Specific findings by pillar follow with sample statements from students.

\section{A. Learning Effectiveness}

According to the literature and our findings, students believe that online learning is an effective and efficient means to achieving an advanced degree. Students in the Community Development Program were extremely impressed with the material in the program, in terms of it being rigorous graduate level work. They also appreciated the direct application of the material to their work. Students appreciated the faculty and diverse viewpoints. No student discussed a breakdown in cohesion or connected curriculum. In fact, students mentioned all of the opportunities the courses provided to them.

This is the first time that I am taking an online course, and I knew it was going to have quite a few readings and writings, but...they have used Power Point... and also some other recordings you can download using your iPod... this has been very helpful for me because listening is a little better than reading...

A project I had due last week was to quantitatively analyze a subject matter, which was interpreted from my employer as analyzing all of our police dispatch records for the purpose of an annexation project that's been going on. So, I was able to gain access to those records...

The literature also indicates the importance of facilitating communication and collaboration in the classroom. When the program began, faculty in the Community Development program cited some 
difficulty with students using the discussion board. Some students hung back and only commented once in awhile. Or, students disappeared and then dropped out of the course. Some non-traditional students discussed their feelings of inadequacy because they had been away from school for awhile or did not know the subject matter as well as others. Faculty addressed this issue at a faculty meeting and provided one another with effective ways to initiate and maintain meaningful communication and collaboration in an online course. Because faculty in this program collaborate so effectively, they often invite one another to guest lecture or join the discussion board in one another's courses. This allows students to see the interconnectedness of the program's courses and institutions.

\section{B. Cost Effectiveness}

One issue that is prevalent in all online graduate programs is the lack of financial assistance. Scholarships and assistantships often readily available for on-campus students are difficult for off-campus students to access. When one of the universities in the inter-institutional programs tried to set up assistantships for its students, it was told by the institution that the students would have to be on-campus or monitored in person by faculty. This requirement is not workable for online students who live hundreds, sometimes thousands, of miles away. Other universities in the program did not research the possibility of having student assistantships, but this issue is being pursued within the program. The literature demonstrates that students in various online programs faced the same issue. Some students in our program cited finances as a reason for dropping or a difficult aspect of the program. Even if students can get financial aid, they do not always have a way to pay it off after they graduate, and are unsure how the degree will pay off for them in the future. One student said that she dropped out because she could not put tuition on her credit card.

I think there [were] at least 2 other people [here] who applied and we just couldn't find funding right way or come up the financial support.

I haven't figured out how I could afford it. I mean the one class is expensive...It's a question of money.

On campus students, obviously, face financial issues as well, but there are more resources available to them, including scholarships and assistantships. What the literature and this study indicates is that there ultimately needs to be more scholarship and assistantship opportunities offered to distance students, particularly graduate students. Before students make the investment in an advanced degree, they want to make sure that it is cost effective for them to enter the program. Iowa State University is looking into ways to offer graduate assistantships to the students in the Online Community Development Program; however, this can be difficult because of the need for institutional oversight.

\section{Access}

Access is an issue for all students. Even with the best high speed Internet, things can go terribly wrong for online students, in terms of problems with technology or lack of access. All of the institutions required Web access, but did not demand high-speed because many students live in rural areas where they cannot get high speed Internet. For students in the Community Development program, simply having a computer at home is an issue. One student drove 60 miles one way to get to a computer with Internet access at the library. This took a toll on her as a single parent and full time employee. She ultimately dropped the program. Other students cited issues with dial-up Internet access. 
If I am home, I have really archaic Internet service. Like, I still have dial-up service that is really bad. I have dial-up service that if I tell it to dial, maybe it will connect in the next hour, maybe it won't. It will maybe stay connected, maybe it won't.

The problem I had is that the attachments were so large that I couldn't get them, and when I did get them, it was very costly to print them out.

For many students in the program, it is not even an issue of cost for high speed Internet; it is an issue regarding phone lines making their way out to their home. This is particularly true for students living on reservations.

\section{Faculty Satisfaction}

Faculty teaching online who also teach on campus can struggle with the overload aspect of teaching distance courses. There may be no compensation for their work, and it means one more thing to do. However, most faculty members enjoy teaching online and the different experience that it offers compared to a traditional classroom. Chat rooms make for interesting places to discuss controversial topics, and students who are non-traditional bring an altogether unique perspective to the classroom. This is very much the case for the faculty in the Community Development program. At faculty meetings they share their excitement about teaching online and want to discuss with others the interesting things they are trying in their classrooms. One professor in the program, who had never taught online before, transferred his lecture into downloadable files for use on an iPod®. He learned a great deal about how to use technology as a teaching tool, and his students gained easy access to his lectures.

At the beginning of the program, faculty from all institutions met at two separate faculty meetings to design curriculum in teams. Faculty worked together through an Appreciative Inquiry process to design a program that included courses on numerous issues in community development. Throughout the faculty meetings, program coordinators also worked to ensure that the multi-institutional, online group began to feel like a real faculty. Faculty members had to interview one another on several topics, including "If you could create the best community development program, what would it look like?" and "What does being part of a great faculty look like to you?" These answers were shared and put on posters around the room to remind everyone of meeting goals, as well as to motivate those in the room. Although some faculty members resisted the process at first, it has served the program well because faculty in this program appreciate one another and work diligently each semester on the curriculum offerings.

This study only included interviews with students, but conversations and meetings indicate that faculty are very satisfied with the progress of the program and are extremely willing to collaborate with faculty from different institutions. In fact, they look forward to it.

\section{E. Student Satisfaction}

From looking at multiple studies regarding student retention in online programs, as well as what students want from their online courses, the same issues cropped up in the Community Development Online Master's Program. Students who are doing well in the program have a lot of support from work and home. They are financially stable and able to pay for their classes without feeling burdened. If they need financial aid, they applied for loans and received them; they also know they can pay off these loans. They have organized a system for time management, and they have reliable, good technology to work with at home. 
Many of the students who dropped out of the Community Development degree program or courses within the program often said they did not have enough time to commit to the program. Non-traditional students in the program often found the reading to be overwhelming and did not foresee the rigor involved in a master's degree program.

I guess I had been investigating opportunities since my employer encourages higher education. I only have a bachelor's and so it works great. It fits in my schedule...I work for a local government, and the hours can be demanding.

It takes more discipline than a regular class. That is one thing that has to be stressed. You also have to have proper connections at home or a place that you can have proper connection. A computer with a good program on it, I have a dial-up computer connection and this instructor likes to send power-point presentations to you and that takes a lot of time to download. Just beware of the limitations. The feedback is not as quick as you want. You send an e-mail or something and you can get a reply back but there is that time lag between when you come up with a question and when you get it answered.

No matter what...you need to prioritize.

Stay up on the work as much as possible. Call instructors right away with problems...they are so supportive.

I did not anticipate the extensive amount of time that I would have to spend on the classes.

Some students also noted that their expectations for the content of the course did not match the reality. Some felt overwhelmed by the material and did not feel prepared. This was echoed by the instructors who said some of their students were struggling and needed tutoring or some preliminary coursework to complete the course.

As one student pointed out, finding time alone to work online can be a struggle.

I didn't have any time...it got to the point to where I didn't have enough time to sleep, and if I can't sleep, I can't do my job. And, if I can't do my job, I can't live.

Other students found it difficult to balance time for coursework and family.

I have an eighteen, ten and 1 year old. It is easy enough for my 18 year old and my 10 year old because they don't particularly want to spend a lot of time with me anyhow. But my wife and my 1 year old just kind of say, "I don't understand why you can't just give us 5 minutes."

Others found time to be an issue from the beginning, and they did not have their books or financial resources in place.

I just didn't put enough time in so that when the classes came on I was[n't] ready to go. 
Some students in the Community Development program had never taken an online course, which made technology a factor as well. However, no students in this study cited that switching from one online learning technology system to another was a problem or a reason for dropping out of the program. In fact, most students appreciated that they were able to work with various professors and practitioners in the field.

Ultimately, students who remained in the program remarked how the instructors' flexibility with assignments and time management allowed them to remain in the program. Instructors also showed understanding about problems with technology.

I was in Vermont last semester when a final paper was due, and I had a lap top that corrupted my paper, but I was able to get it to her within a couple of days. I had to redo a lot of it.... and it turned out that the bibliography needed some work, and she was okay with that.

[The professor] was amazing. She was always there when you needed her. She really understood what the distance students were going through and adapted the course as necessary.

[The professor] has been tremendously flexible.

I would say I have had excellent help and communication [from the instructors].

Finally, there are many issues that are out of people's control that come up when working with several adult, non-traditional students in an online program. People get sick, have family issues to attend to, or simply have personal situations that make being a successful student a struggle.

I have multiple-sclerosis, and I have had a few bad days the last weeks. I have been just swamped with work so it is hard to keep up.

\section{SUMMARY AND CONCLUSIONS}

The information from our study says that inter-institutional programs do not create additional barriers for students; rather they have the same issues as students enrolled in programs offered through one institution. Using the pillars as a framework for analyzing our data, we can identify specific strategies for enhancing the quality of the Community Development program and other distance programs as well. For the Community Development program specifically, we need to communicate more with students about the program and their experience, offer more information about financial aid, loans, and scholarships for graduate distance students, understand the technology limitations students are facing, help students manage their time more effectively, offer an orientation session for new students, and finally help students formulate realistic expectations for the program so they can successfully finish their coursework. In response to these suggestions, we created an online newsletter for the program that has helped students feel like they are part of a program, generated additional enrollments, and addressed some of the unspoken issues identified in the interviews.

Our findings come from an admittedly small sample, yet we feel this study provides an important first step to creating a better understanding of how inter-institutional programs work and how students experience them. Overall, students in the evaluation process did not mention that switching between 
university systems and teaching technology posed a problem. As long as they had someone they could contact for help at any given time, flexibility with their coursework, and understanding about their life situation, they had a positive experience in the program. Thus for our program, the student experiences in an inter-institutional online program looks virtually the same as those in a program offered by one university. With progressive faculty in their respective fields coming from five accredited state university, students in the Community Development Online Master's Program do have great opportunities to earn their master's degree and hone their skills as a practitioner, while staying in their home community.

\section{ABOUT THE AUTHORS}

Susan Fey is Program Coordinator at the North Central Regional Center for Rural Development. She provides leadership for the Community Development On-line Master's Program, as well as coordinating other projects and publications at the Center. She received her B.A. in Education and English from Iowa State University and her M.A. in English from Iowa State University. Susan has published articles and practical guides on community development; currently she is working with Drs. Cornelia and Jan Flora on the 3rd Edition of Rural Communities: Legacy and Change.

Dr. Mary Emery is Associate Director of the North Central Regional Center for Rural Development. She provides leadership for the Community Development On-line Master's Program and also teaches courses in the program. She received her doctorate from Rutgers University. Mary has published several articles and practioners' guides on community development. Her most recent publication with Susan Fey and Dr. Cornelia Flora is "Using Community Capitals to Build Assets for Positive Community Change," published in CD Practice.

Dr. Cornelia Butler Flora is Director of the North Central Regional Center for Rural Development and is the Charles F. Curtiss Distinguished Professor of Agriculture and Sociology. She is a faculty member at Iowa State University and is the faculty chair for and teaches in the Community Development On-line Master's Program. She received her doctorate from Cornell University. She has authored and co-authored a vast amount of publications; currently she is working with Dr. Jan Flora and Susan Fey on the 3rd Edition of Rural Communities: Legacy and Change.

\section{REFERENCES}

1. Valenta, A., D. Therriault, M. Dieter, and R. Mrtek. Identifying student attitudes and learning styles in distance education. Journal of Asynchronous Learning Networks 5(2): 111-127, 2001. Online: http://www.sloan-c.org/publications/jaln/index.asp.

2. Smart, K. L. and J. J. Cappel. Students' perceptions of online learning: A comparative study. Journal of Information Technology Education 5: 201-219, 2006.

3. Wilde, M. L. and A. Epperson. A survey of alumni of LIS distance education programs: Experiences and implications. The Journal of Academic Librarianship 32(3): 238-250, 2006.

4. Moore, J. C. The Sloan Consortium Quality Framework and the Five Pillars. Needham, MA: The Sloan Consortium, 2005. Online: http://www.sloan-c.org/publications/books/qualityframework.pdf.

5. Michael, S. O. and L. Balraj. Higher education institutional collaborations: An analysis of joint degree programs. Journal of Higher Education Policy and Management 25(2): 131-145, 2003.

6. Moxley, V. Inter-Institutional Distance Education Alliances: When, Why, Who, and How. Presentation for the $21^{\text {st }}$ Annual Conference on Distance Teaching and Learning, Madison, Wisconsin, 2005. 
7. Lapping, K, D. Marsh, J. Rosenbaum, E. Swedberg, J. Sternin, M. Sternin, and D. Schroeder. The positive deviance approach: Challenges and opportunities for the future. Food and Nutrition Bulletin 23(4): 128-135, The United Nations University, 2002.

Online: http://64.233.161.104/search?q=cache:g2EwYvyv2YMJ:www.positivedeviance.org/p.

8. Magruder, J. and B. Rohr. Appreciative Inquiry: Change at the Speed of Imagination. San Francisco: Jossey-Bass, 2001.

9. Piercy, K. and T. Lee. Graduate distance education in family relations: A case study, Family Relations 55(1): 67-79, 2006.

10. Nash, R. D. Course completion rates among distance learners: identifying possible methods to improve retention. Online Journal of Distance Learning Administration VIII (IV): 2005.

Online: http://www.westga.edu/\%7Edistance/ojdla/winter84/nash84.htm.

11. Garland, M. Ethnography penetrates the "I didn't have time" rationale to elucidate higher order reasons for distance education withdrawal. Research in Distance Education 5(1-2): 6-10, 1993.

12. Bee, R. H. Differing attitudes of economics students about web-based instruction. College Student Journal 32(2): 258-269, 1998.

13. Lao, T. and C. Gonzales. Understanding online learning through a qualitative description of professors and students' experiences. Journal of Technology and Teacher Education 13(3): 459-474, 2005.

14. Flora, C. B. Information technology critical as rural and remote areas transition to the new economy. Rural Development News 28(2): 1-2, 2006.

Online: http://www.ncrcrd.iastate.edu/newsletter/Vol28No2-2006/neweconomy.htm.

15. Pierrakeas, C., M. Xenos, C. Panagiotakopoulos and D. Vergidis. A comparative study of droupout rates and causes for two different distance education courses. The International Review of Research in Open and Distance Learning 5(2): 2004.

Online: http://www.irrodl.org/index.php/irrodl/article/view/183/265.

16. Williams, P. and D. Nichols. E-learning: what the literature tells us about distance education. Aslib Proceedings: New Information Perspectives 57(2): 109-122, 2004.

17. Powell, R., C. Conway, and L. Ross. Effects of Predisposing Characteristics on Student Success. Journal of Distance Education 5(1): 5-19, 1990.

Online: http://www.jofde.ca/index.php/jde/article/view/368/259.

18. Atack, L. Becoming a web-based learner: registered nurses' experiences. Issues and Innovations in Nursing Education 44(3): 289-297, 2003.

19. Swan, K., J. Shen, and S. Roxanne Hiltz. Assessment and Collaboration in Online Learning. Journal of Asynchronous Learning Networks 10(1): 2006.

20. Garrison, D. R. “Online Collaboration Principles." Journal of Asynchronous Learning Networks 10(1): 2006.

21. Haythornthwaite, C. "Facilitating Collaboration in Online Learning." Journal of Asynchronous Learning Networks 10(1): 2006.

22. Fung, Y.Y.H. Collaborative online learning: interaction patterns and limiting factors. Open Learning 19(2): 135-149, 2004. 